\title{
Tooth Loss and Its Association With Frequency of Pregnancy: A Cross-Sectional Study Among Yemeni Women
}

Anas Shamala ( $\square$ anasshamala@gmail.com )

Department of Preventive and Biomedical Science, College of Dentistry, University of Science \& Technology

\section{Ebtesam Al-Maimooni}

Department of Preventive and Biomedical Science, College of Dentistry, University of Science \& Technology

\section{Salsbeel Al-Matari}

Department of Preventive and Biomedical Science, College of Dentistry, University of Science \& Technology

\section{Ryhana Hiyat}

Postgraduate Program, School of Dental Science, Universiti Sains Malaysia

\section{Mohammed Al-wesabi}

Department of Preventive and Biomedical Science, College of Dentistry, University of Science \& Technology

\section{Sadeq Al-Maweri}

Department of Oral Medicine and Diagnostic Sciences, AlFarabi College of Dentistry and Nursing,

\section{Mohammad Nassani}

Department of Restorative and Prosthetic Dental Sciences, College of Dentistry, Dar Al Uloom University

\section{Esam Halboub}

5Department of Maxillofacial Surgery and Diagnostic Sciences, College of Dentistry, Jazan University

\section{Research Article}

Keywords: Giving birth pregnant, tooth loss, khat chewing, Yemen

Posted Date: January 18th, 2021

DOl: https://doi.org/10.21203/rs.3.rs-147421/v1

License: (1) (i) This work is licensed under a Creative Commons Attribution 4.0 International License.

Read Full License 


\section{Abstract}

Backgrounds: The present study sought to assess tooth loss and oral hygiene practices among a sample of Yemeni women in association with giving births (parity).

Subjects and Methods: This cross-sectional study included a sample of 644 Yemeni women. They were interviewed to gather socio-demographic (age, education, number of children) and behavioral data (oral hygiene practices, khat chewing and smoking). Additionally, they were examined clinically to assess number of tooth loss. Data were analyzed using SPSS with a P-value $<0.05$ was considered statistically significant.

Results: The participating women aged between 16 and 51 years. Only one fifth of the sample reported brushing their teeth regularly (i.e, at least once a day), and around $36.8 \%$ reported using dental aids occasionally. Additionally, $52 \%$ and $21 \%$ of the sample reported they were khat chewers and smokers, respectively. The mean number of tooth loss was 4.7 . The mean number of children was 4.15 , with approximately $54 \%$ of the participating women had more than 3 children. The results of the logistic regression revealed a significant association between number of children and tooth loss.

Conclusion: Yemeni women had poor oral hygiene practices and high prevalence of tooth loss increased proportionally with the increased number of children. This emphasizes the importance of an effective oral hygiene motivation and health education among female patients during pregnancy periods.

\section{Introduction}

Dental diseases are amongst the most prevalent health issues worldwide (1). In particular, the tooth loss is a significant health burden that gravely impacts the patients' quality of life(2). Tooth loss is considered a marker of both periodontal disease and dental caries, though teeth can be lost due to other reasons such as trauma(3). The former, periodontal disease, is a very common chronic condition affecting a considerable proportion of the adult population worldwide(4). It is characterized by progressive inflammatory destruction of tooth-supporting structures in response to dental biofilm $(5,6)$. If untreated, periodontal disease may progress, destroying soft and hard tissues surrounding the tooth, causing attachment loss, tooth mobility and eventually tooth loss and edentualism $(4,7)$. The current evidence suggests that periodontal disease/tooth loss is a risk factor for several systemic diseases such as rheumatoid arthritis, atherosclerosis, respiratory diseases, and non-alcoholic fatty liver disease(8-12). it is recognized that dental plaque (biofilm) is the main causative agent for periodontal diseases(6). However, a plethora of factors including poor oral hygiene, tobacco use, alcohol consumption, advanced age, low socioeconomic status, stress, and systemic conditions such as diabetes mellitus, obesity, and osteoporosis, and pregnancy have been reported to increase the risk and severity of periodontitis(13-18).

Pregnancy, a physiological phenomenon, has been reported as a risk factor for oral diseases including periodontitis (19-22). It is associated with several hormonal changes that alter the gingival response to dental plaque, thus increasing its susceptibility to gingival inflammation and periodontal diseases $(20,22$, 
23). Several studies have reported greater gingival inflammation during pregnancy $(19,21,22)$ and other studies reported a positive association between number of giving births and tooth loss (24-26).

In Yemen, the prevalence of dental diseases such as periodontitis, dental caries and tooth loss is amongst the highest in the world $(16,27,28)$. This might be ascribed to the poor socioeconomic status, high prevalence of tobacco use and chewing habits, and limited human resources $(16,29-31)$. In fact, however, the studies on periodontal health status among Yemeni populations -especially among womenare very scarce, and mostly limited to the assessment of oral diseases among males in relation to local oral habits, namely smokeless tobacco and qat chewing $(16,27,28,31,32)$. Although the fertility rate in Yemen is considered among the highest in the world, no any attempt has been made to assess the relationship between frequency of pregnancy and oral health status among Yemeni women. Availability of such information is very important for planning public health prevention and promotion programs. Hence, the present study sought to: 1 ) assess oral health status (using tooth loss as a proxy indicator) of Yemeni women, and 2) determine the relationship between tooth loss and frequency of pregnancy/giving birth among Yemeni women.

\section{Subjects And Methods}

This study was of an observational cross-sectional design. The study protocol was reviewed and approved by the research ethical committee at the University of Science and Technology (UST), Sanaa, Yemen (No: EAC/UST179). The target population was women who attended the dental clinics, College of Dentistry, UST, Sana'a, Yemen. The study was conducted during the 2018-2019 academic year: from November 2018 to April 2019. The sample size was calculated using version 3.01 of OpenEpi software for epidemiologic statistics (Bill and Melinda Gates Foundation, Emory University, Atlanta, Georgia, USA); the required sample size for $95 \%$ confidence level and power of $80 \%$, was 424 subjects

Women were included if they aged above 16 years and had a previous history of pregnancy. Women who were medically compromised, had extraction because of previous orthodontic treatment or were out of the said age range were excluded.

The participants were informed about the study aims and procedures and asked to provide their consentto-participate anonymously. The participant's sheet comprised questions related to age, education, qat chewing, smoking, oral hygiene practices, and oral hygiene aids. The sheet included also items about frequency of pregnancy along with the number of children as to take account for the chance of premature birth.

The number of missing teeth was evaluated by two well-trained dentists using a sterile dental examination kit under artificial light of the dental chair.

Intra- and inter-examiner agreements were conducted on fifty cases in two different occasions with a week interval. Kappa statistic revealed a perfect intra-examiner agreement (1) and a high level of interexaminer reliability (0.9). 
The analysis of the collected data was carried out using the SPSS statistical package (IBM SPSS Statistics for Windows, Version 20.0, Released 2011, IBM Corp, Armonk, New York, USA). The demographics and other characteristics of study population were presented as frequency with proportion and mean with standard deviation, as appropriate. The bivariate analyses were done using independent ttest or ANOVA to identify any potential differences in the mean number of missing teeth between two or more different subgroups, respectively. Spearman's correlation analysis was applied in order to identify any correlations between number of "missing teeth" and "number of children/frequency of pregnancy/interval of pregnancy." A logistic regression analysis was conducted to determine the independent determinants of tooth loss among study population while adjusting for the potential confounding factors. The outcome variable was "number of missing teeth", and level of education, oral health practices including frequency of tooth brushing and using interdental aids, gum bleeding, periodontal treatment, number of children, interval between pregnancy were considered as independent variables (determinants). Odd ratios (ORs) and their $95 \%$ confidence intervals (Cls) were calculated, and the significance level was set at $P<0.05$.

\section{Results}

In total, 644 women (age range: $16-51$ years) participated in the present study; most of the participants aged between $30-40$ years $(288,44.7 \%), 28.9 \%$ were older than 40 years, and $26.4 \%$ were less than 30 years old. Around $46.2 \%$ were illiterate, $40.7 \%$ got high school education, and only $13.2 \%$ got University education. Only one fifth of the sample reported brushing their teeth regularly (i.e, at least once a day), and around $36.8 \%$ reported occasionally using one type of oral hygiene aids. Additionally, $52 \%$ and $21 \%$ of the sample were qat chewers and smokers, respectively. The mean number of children was 4.15 , with $53.6 \%$ of the participating women having more than 3 children (Table 1 ). 
Table 1

Demographics and general characteristics of the study sample

\begin{tabular}{|c|c|c|c|}
\hline & & $\mathbf{N}$ & $\%$ \\
\hline \multirow[t]{3}{*}{ Age } & Less than 30 years & 170 & $26.4 \%$ \\
\hline & $30-40$ years & 288 & $44.7 \%$ \\
\hline & More than 40 years & 186 & $28.9 \%$ \\
\hline \multirow[t]{3}{*}{ Level of education } & Illiterate & 297 & $46.2 \%$ \\
\hline & High school & 262 & $40.7 \%$ \\
\hline & University & 85 & $13.2 \%$ \\
\hline \multirow[t]{4}{*}{ Frequency of tooth brushing } & Never & 178 & $27.8 \%$ \\
\hline & 1 time per week & 294 & $45.7 \%$ \\
\hline & 2 or 3 times per week & 41 & $6.4 \%$ \\
\hline & At least once daily & 130 & $20.1 \%$ \\
\hline \multirow[t]{4}{*}{ Oral hygiene aids } & None & 407 & $63.2 \%$ \\
\hline & Dental floss & 49 & $7.6 \%$ \\
\hline & Interdental brush & 115 & $17.9 \%$ \\
\hline & Mouthwash & 73 & $11.3 \%$ \\
\hline \multirow[t]{2}{*}{ Gum bleeding when brushing } & No & 72 & $11.1 \%$ \\
\hline & Yes & 394 & $61.2 \%$ \\
\hline \multirow[t]{2}{*}{ Pervious periodontal treatment } & No & 422 & $65.5 \%$ \\
\hline & Yes & 222 & $34.5 \%$ \\
\hline \multirow[t]{2}{*}{ Smoking } & No & 495 & $76.9 \%$ \\
\hline & Yes & 149 & $23.1 \%$ \\
\hline \multirow[t]{2}{*}{ Qat chewing } & No & 309 & $48.0 \%$ \\
\hline & Yes & 335 & $52.0 \%$ \\
\hline \multirow[t]{2}{*}{ Number of children } & $<=3$ children & 299 & $46.4 \%$ \\
\hline & $>3$ children & 345 & $53.6 \%$ \\
\hline \multirow[t]{2}{*}{ Interval of pregnancy } & $<=4$ years & 556 & $86.3 \%$ \\
\hline & $>4$ years & 88 & $13.7 \%$ \\
\hline
\end{tabular}


The mean number of missing teeth among the sample was 4.7. As presented in Table 2 and 3 , the bivariate analysis results showed a statistically significant association between mean number of missing teeth and age, level of education, frequency of tooth brushing, oral hygiene aids type, bleeding on brushing, number of children and interval between pregnancy. 
Table 2

Bivariate analysis of missing teeth (mean number of missed teeth) by independent factors

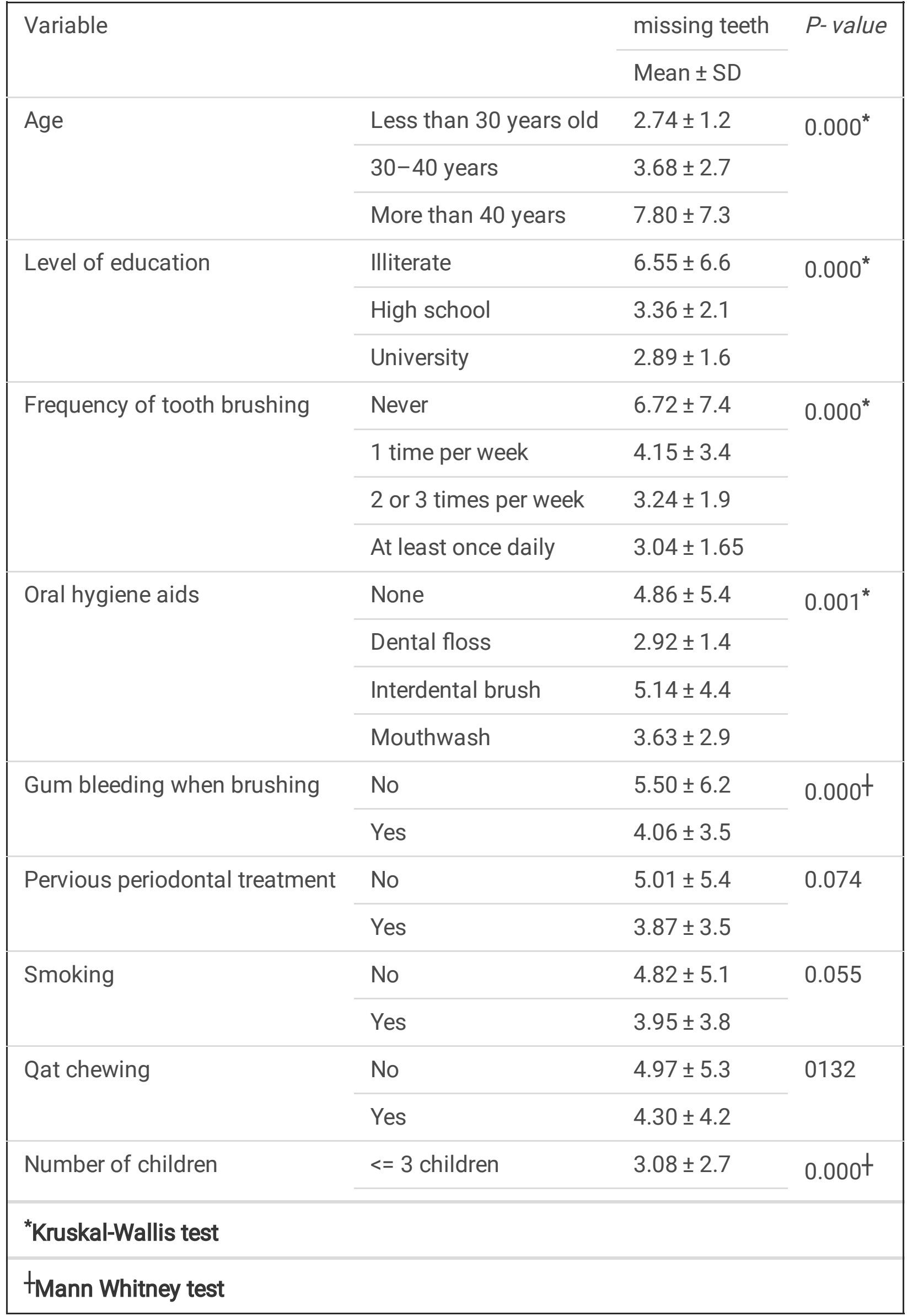




\begin{tabular}{|c|c|c|c|}
\hline & $>3$ children & $5.95 \pm 5.8$ & \\
\hline \multirow[t]{2}{*}{ Interval between pregnancy } & $<=4$ years & $4.88 \pm 5.1$ & \multirow[t]{2}{*}{$0.000 t$} \\
\hline & $>4$ years & $2.95 \pm 1.5$ & \\
\hline \multicolumn{4}{|l|}{${ }^{*}$ Kruskal-Wallis test } \\
\hline
\end{tabular}


Table 3

Bivariate analysis of the association between number of missing teeth and independent factors.

\begin{tabular}{|c|c|c|c|c|c|c|c|c|}
\hline \multirow[t]{3}{*}{ Variable } & & \multicolumn{6}{|c|}{ Missing teeth } & \multirow[t]{3}{*}{$\begin{array}{l}P \text { - } \\
\text { value }\end{array}$} \\
\hline & & \multicolumn{2}{|c|}{$<=$ or 5} & \multicolumn{2}{|c|}{$6-10$} & \multicolumn{2}{|l|}{$>10$} & \\
\hline & & $\mathrm{F}$ & $\%$ & $\mathrm{~F}$ & $\%$ & $\mathrm{~F}$ & $\%$ & \\
\hline \multirow[t]{3}{*}{ Age } & $\begin{array}{l}\text { Less than } \\
30 \text { years old }\end{array}$ & 160 & $32.0 \%$ & 10 & $10.4 \%$ & 0 & $0.0 \%$ & \multirow[t]{3}{*}{$0.000^{*}$} \\
\hline & $30-40$ years & 243 & $48.6 \%$ & 37 & $38.5 \%$ & 8 & $16.7 \%$ & \\
\hline & $\begin{array}{l}\text { More than } \\
40 \text { years }\end{array}$ & 97 & $19.4 \%$ & 49 & $51.0 \%$ & 40 & $83.3 \%$ & \\
\hline \multirow[t]{3}{*}{ Level of education } & Illiterate & 194 & $38.8 \%$ & 59 & $61.4 \%$ & 44 & $91.7 \%$ & \multirow[t]{3}{*}{$0.000^{*}$} \\
\hline & High school & 227 & $45.4 \%$ & 31 & $32.3 \%$ & 4 & $8.3 \%$ & \\
\hline & University & 79 & $15.8 \%$ & 6 & $6.2 \%$ & 0 & $0.0 \%$ & \\
\hline \multirow{4}{*}{$\begin{array}{l}\text { Frequency of tooth } \\
\text { brushing }\end{array}$} & Never & 115 & $23.0 \%$ & 33 & $34.4 \%$ & 30 & $63.8 \%$ & \multirow[t]{4}{*}{$0.000^{*}$} \\
\hline & 1 time per week & 231 & $46.2 \%$ & 49 & $51.0 \%$ & 14 & $29.8 \%$ & \\
\hline & $\begin{array}{l}2 \text { or } 3 \text { times per } \\
\text { week }\end{array}$ & 37 & $7.4 \%$ & $2.1 \%$ & 2 & $4.3 \%$ & & \\
\hline & $\begin{array}{l}\text { At least once } \\
\text { daily }\end{array}$ & 117 & $23.4 \%$ & 12 & $12.5 \%$ & $2.1 \%$ & & \\
\hline \multirow[t]{4}{*}{ Oral hygiene aids } & None & 313 & $62.6 \%$ & 59 & $61.5 \%$ & 35 & $72.9 \%$ & \multirow[t]{4}{*}{$0.009^{*}$} \\
\hline & Dental floss & 46 & $9.2 \%$ & $3.1 \%$ & 0 & $0.0 \%$ & & \\
\hline & $\begin{array}{l}\text { Interdental } \\
\text { brush }\end{array}$ & 79 & $15.8 \%$ & 26 & $27.1 \%$ & 10 & $20.8 \%$ & \\
\hline & Mouthwash & 62 & $12.4 \%$ & 8 & $8.3 \%$ & 3 & $6.2 \%$ & \\
\hline \multirow{2}{*}{$\begin{array}{l}\text { Gum bleeding } \\
\text { when brushing }\end{array}$} & No & 184 & $36.8 \%$ & 37 & $38.5 \%$ & 29 & $60.4 \%$ & \multirow[t]{2}{*}{$0.006 t$} \\
\hline & Yes & 316 & $63.2 \%$ & 59 & $61.5 \%$ & 19 & $39.6 \%$ & \\
\hline \multirow{2}{*}{$\begin{array}{l}\text { Pervious } \\
\text { periodontal } \\
\text { treatment }\end{array}$} & No & 314 & $62.8 \%$ & 70 & $72.9 \%$ & 38 & $79.2 \%$ & \multirow[t]{2}{*}{$0.019 t$} \\
\hline & Yes & 186 & $37.2 \%$ & 26 & $27.1 \%$ & 10 & $20.8 \%$ & \\
\hline Smoking & No & 375 & $75.0 \%$ & 79 & $82.3 \%$ & 41 & $85.4 \%$ & 0.103 \\
\hline \multicolumn{9}{|l|}{ *Kruskal-Wallis test } \\
\hline
\end{tabular}




\begin{tabular}{|lllllllll|}
\hline & Yes & 125 & $25.0 \%$ & 17 & $17.7 \%$ & 7 & $14.6 \%$ & \\
\hline \multirow{2}{*}{ Qat chewing } & No & 231 & $46.2 \%$ & 52 & $54.2 \%$ & 26 & $54.2 \%$ & 0.241 \\
\cline { 2 - 8 } & Yes & 269 & $53.8 \%$ & 44 & $45.8 \%$ & 22 & $45.8 \%$ & \\
\hline $\begin{array}{l}\text { Number of } \\
\text { children }\end{array}$ & $<=3$ children & 276 & $55.2 \%$ & 19 & $19.8 \%$ & 4 & $8.3 \%$ & $0.000+$ \\
\cline { 2 - 8 } & $>3$ children & 224 & $44.8 \%$ & 77 & $80.2 \%$ & 44 & $91.7 \%$ & \\
\hline Interval & $<=4$ years & 419 & $83.8 \%$ & 89 & $92.7 \%$ & 48 & $100.0 \%$ & $0.001+$ \\
\cline { 2 - 7 } & $>4$ years & 81 & $16.2 \%$ & 7 & $7.3 \%$ & 0 & $0.0 \%$ & \\
\hline *Kruskal-Wallis test & & & & & & & & \\
\hline tMann Whitney test & & & & & & & & \\
\hline
\end{tabular}

Table 4 illustrates the results of the logistic regression analysis which reveal the determinant factors for the number of missing teeth. The results showed that the number of children and age of participating women were the only independent determinants for number of missing teeth $(P<0.01)$. 
Table 4

Logistic regression of the predictors factors of missing teeth.

\begin{tabular}{|c|c|c|c|c|c|c|}
\hline \multirow{3}{*}{ Education (ref: "Illiterate") } & \multirow[t]{2}{*}{ B } & \multirow[t]{2}{*}{ S.E. } & \multirow[t]{2}{*}{ P-value } & \multirow[t]{2}{*}{ Odds ratio } & \multicolumn{2}{|c|}{ 95\% C.I.for OR } \\
\hline & & & & & Lower & Upper \\
\hline & & & & & & \\
\hline High school & .926 & .336 & 7.612 & 1 & .006 & 2.525 \\
\hline University & .565 & .331 & 2.914 & 1 & .088 & 1.760 \\
\hline \multicolumn{7}{|c|}{ Interdental aids (ref: "None”) } \\
\hline Dental floss & .061 & .302 & .839 & 1.063 & .589 & 1.920 \\
\hline Interdental brush & $-.718-$ & .472 & .128 & .488 & .194 & 1.229 \\
\hline Mouthwash & .352 & .358 & .326 & 1.422 & .704 & 2.869 \\
\hline \multicolumn{7}{|l|}{ Gum bleeding (ref:"No") } \\
\hline & $-.254-$ & .193 & .188 & .776 & .531 & 1.132 \\
\hline \multicolumn{7}{|l|}{ Periodontal treatment } \\
\hline & $-.012-$ & .198 & .951 & .988 & .670 & 1.457 \\
\hline \multicolumn{7}{|l|}{ Medical history } \\
\hline & .330 & .299 & .270 & 1.391 & .774 & 2.500 \\
\hline \multicolumn{7}{|l|}{ Number of children } \\
\hline & .769 & .215 & .000 & 2.157 & 1.416 & 3.286 \\
\hline \multicolumn{7}{|l|}{ Interval } \\
\hline & -.309 & .304 & .309 & .734 & .405 & 1.332 \\
\hline \multicolumn{7}{|c|}{ Age (ref: "Less than 30 years old") } \\
\hline $30-40$ years & .563 & .254 & .027 & 1.756 & 1.067 & 2.889 \\
\hline More than 40 years & 1.331 & .293 & .000 & 3.785 & 2.134 & 6.716 \\
\hline \multicolumn{7}{|c|}{ Frequency of tooth brushing (ref: "Never") } \\
\hline 1 time per week & .235 & .229 & .304 & 1.265 & .808 & 1.981 \\
\hline 2 or more times per week & .047 & .269 & .862 & 1.048 & .618 & 1.777 \\
\hline
\end{tabular}

\section{Discussion}


To the best of our knowledge, this is the first study that evaluated the oral health status and its relationship with frequency of pregnancy, giving birth and other independent variables among a sample of Yemeni women. We considered tooth loss as a proxy indicator of oral health (dependent variable). In fact, tooth loss is an ultimate marker of dental and periodontal diseases, though teeth can be lost due to other reasons such as trauma (3). Overall, the results showed a significant association between the number of children and number of tooth loss after controlling the other potential confounders.

Additionally, the results revealed poor oral hygiene practices (only one fifth reported brushing their teeth regularly) as well as a high prevalence of oral habits namely qat chewing (52\%) and smoking (23\%), among Yemeni women.

The main result of the present study is a positive association between the number of children and tooth loss, a finding which is consistent with the results of many previous studies from other countries that reported a significant association between number of children and periodontal disease/tooth loss $(20,25$, $26,33-36)$. The positive association between these two phenomena could be explained by many biological mechanisms. The first plausible explanation is the increase of progesterone and estrogen hormones during pregnancy which lead to vascular permeability and minimal host modulation and thus increasing susceptibility to dental and periodontal infections (37). In addition, the limited access to dental health care owing to socioeconomic factors, especially in developing countries, could affect the oral health status; the effect of this factor magnifies with repeated pregnancy and giving births. Reports from the US indicate that more than $50 \%$ of pregnant women did not receive dental care during their recent pregnancy (37).

Another important finding of the present study is the lack of association between the number of missing teeth and both qat chewing and smoking habits. Qat chewing (also known as khat), a deeply rooted social habit in Yemen and some East African countries (38), has been reported to have several detrimental effects on oral and dental tissues including keratotic mucosal lesions, periodontitis, teeth attrition, and temporomandibular joint disorders (38-41). In contrast to our findings, most of the previous studies conducted on adult Yemeni males implicated qat chewing as a risk factor for periodontal signs/diseases including gingivitis, attachment loss, deep pockets and tooth loss $(16,29-31)$. With regard to smoking, the present study did not find a significant association with tooth loss, and this is consistent with a recent study conducted in Yemen (16), but contradicts other studies elsewhere that reported smoking as a significant risk factor for periodontal diseases and tooth loss (42). Such unexpected findings can be ascribed to the fact that the relationship between periodontal diseases and both qat chewing and smoking is dose-dependent response; that said, the relationship depends on many factors such as the duration of the habit practice (in years), duration per day (for qat chewing ), and frequency of chewing/smoking (43).

Unfortunately, no detailed information was obtained about the intensity/duration of these habits although $53 \%$ and $23 \%$ reported qat chewing and smoking, respectively. Another possible explanation is the negative response given by Yemeni women regarding practicing these habits due to the delicacy of 
this subject for cultural reasons. Thus, the real prevalence of these habits might have been underestimated.

Apart from the negative results of the present study, the deleterious effects of smoking and qat chewing on oral and systemic health have been well documented $(38,39)$. Hence, dental practitioners can play a pivotal role in reducing the deleterious effects of these habits. They have a commitment of educating their patients about the harmful consequences of such habits and providing them tobacco/qat cessation advice to help them quit the habits (44) .

The current study provides an insight on oral health status (using tooth loss as indicator) among a sample of Yemeni women and supports the association between the number of children and tooth loss. In line with the previous literature, the results of the present study found a significant positive association between tooth loss and advance age and low education level. However, the present study has several limitations that should be taken into consideration. These include the following: the nature of study design (being cross-sectional study), and hence the causality cannot be established; recall bias; and lack of reliable medical and dental records, or more accurate investigative tools to decrease the confounding factors such as systemic diseases.

In summary, the current study revealed poor oral hygiene practices and high prevalence of tooth loss among Yemeni women. Of utmost importance, the higher the number of children the Yemeni women have, the higher the number the tooth loss they have. This emphasizes the importance of an effective oral hygiene motivation and health education among Yemeni women at pregnancy periods. Further largescale studies are also recommended.

\section{Declarations}

\section{Consent to participate:}

All participants anonymously accept in informed consent their participation age between 18-51 years, for those who their age 16-17 years or illiterate, their spouses or parents' gave their informed consent for acceptance and signature of confirmation to participate was taken after clarifying the aim of research and the main objectives

\section{Guidelines and regulations :}

All methods and research protocol carried out according to ethical and scientific guidelines and regulations.

\section{Ethics approval :}

The study protocol was reviewed and approved by the research ethical committee at the University of Science and Technology (UST), Sanaa, Yemen (No: EAC/UST179). 
Availability of data and materials:

The materials and data supporting the results of the current study will be available upon request from the corresponding author "Anas Shamala" and in the supporting file immediately after obtaining acceptance for publication.

\section{Consent for publication:}

Not applicable

\section{Author contribution:}

Anas Shamala and Sadeq Ali Al-Maweri designed The present study and the main conceptual ideas, drafted the manuscript, provided critical feedback, helped shape the research, and supervising the diagnosis process. Ebtesam Al-Maimooni, Salsbeel Al-Matari, and Ryhana Hiyat carried out the investigation and diagnosis process and measurements that were under supervision, provided critical feedback and helped shape the research, and contributed to the final manuscript. Mohammed Al-wesabi and Esam Halboub carried out the program manipulation and measurements and discussed the results and contributed to the final manuscript. Mohammad Zakaria Nassani re-write the manuscript depending on the feedback and preparing it for publication and discussed the results and contributed to the final manuscript.

\section{Funding:}

the authors declare no funding

\section{Competing interests:}

Authors have no conflicts of interest to disclose.

\section{Acknowledgements:}

The authors thank the academic colleagues and administrative staff of the College of Dentistry, University of Science and Technology, Sana'a, Yemen for their support and assistance during the dental examination process for all participants.

\section{References}

1. Righolt A, Jevdjevic M, Marcenes W, Listl S. Global-, regional-, and country-level economic impacts of dental diseases in 2015. Journal of Dental Research. 2018;97(5):501-7.

2. Schierz O, Baba K, Fueki K. Functional Oral Health-Related Quality of Life Impact: A Systematic Review in Populations with Tooth Loss. Journal of Oral Rehabilitation. 2020. 
3. Pihlstrom BL, Michalowicz BS, Johnson NW. Periodontal diseases. The lancet. 2005;366(9499):180920.

4. Papapanou PN, Susin C. Periodontitis epidemiology: is periodontitis under-recognized, overdiagnosed, or both? Periodontology 2000. 2017;75(1):45-51.

5. Murakami S, Mealey BL, Mariotti A, Chapple IL. Dental plaque-induced gingival conditions. Journal of clinical periodontology. 2018;45:S17-S27.

6. Curtis MA, Diaz PI, Van Dyke TE. The role of the microbiota in periodontal disease. Periodontology 2000. 2020;83(1):14-25.

7. Meyle J, Chapple I. Molecular aspects of the pathogenesis of periodontitis. Periodontology 2000. 2015;69(1):7-17.

8. Beukers NG, van der Heijden GJ, van Wijk AJ, Loos BG. Periodontitis is an independent risk indicator for atherosclerotic cardiovascular diseases among 60174 participants in a large dental school in the Netherlands. J Epidemiol Community Health. 2017;71(1):37-42.

9. de Oliveira Ferreira R, de Brito Silva R, Magno MB, Carvalho Almeida APCPS, Fagundes NCF, Maia LC, et al. Does periodontitis represent a risk factor for rheumatoid arthritis? A systematic review and meta-analysis. Therapeutic advances in musculoskeletal disease. 2019;11:1759720X19858514.

10. Moghadam SA, Shirazaiy M, Risbaf S. The associations between periodontitis and respiratory disease. Journal of Nepal Health Research Council. 2017;15(1):1-6.

11. Alakhali MS, Al-Maweri SA, Al-Shamiri HM, Al-haddad K, Halboub E. The potential association between periodontitis and non-alcoholic fatty liver disease: A systematic review. Clinical oral investigations. 2018;22(9):2965-74.

12. Bui FQ, Almeida-da-Silva CLC, Huynh B, Trinh A, Liu J, Woodward J, et al. Association between periodontal pathogens and systemic disease. biomedical journal. 2019.

13. Moeintaghavi A, Arab HR, Rezaee SAR, Naderi H, Shiezadeh F, Sadeghi S, et al. The effects of smoking on expression of IL-12 and IL-1 $\beta$ in gingival tissues of patients with chronic periodontitis. The open dentistry journal. 2017;11:595.

14. Jaiswal R, Shenoy N, Thomas B. Evaluation of association between psychological stress and serum cortisol levels in patients with chronic periodontitis-Estimation of relationship between psychological stress and periodontal status. Journal of Indian Society of Periodontology. 2016;20(4):381.

15. Shamala A, Al-Hajri M, Al-Wesabi A. Risk factors for periodontal diseases among Yemeni type II diabetic patients. A case-control study. Journal of Oral Research. 2017;6(7):176-81.

16. Al-Hajj W, Hwaiti H, Shamala A, Al-Azazi H, Alwesabi M. Association of Khat chewing, smoking, age and sex with periodontal status among Yemeni adults. Brazilian Dental Science. 2020;23(1):8.

17. Kalakonda B, Al-Maweri S-A, Al-Shamiri H-M, ljaz A, Gamal S, Dhaifullah E. Is Khat (Catha edulis) chewing a risk factor for periodontal diseases? A systematic review. Journal of Clinical and Experimental Dentistry. 2017;9(10):e1264. 
18. Dhaifullah E, Al-Maweri SA, Koppolu P, Elkhtat E, Mostafa D, Mahgoub M. Body mass index and periodontal health status among young Saudi adults: a cross-sectional study. Annals of Saudi Medicine. 2019;39(6):433-40.

19. Adesina KT, Ernest MA, Tobin AO, Isiaka-Lawal SA, Adeyemi MF, Olarinoye AO, et al. Oral health status of pregnant women in Ilorin, Nigeria. Journal of Obstetrics and Gynaecology. 2018;38(8):1093-8.

20. Laine MA. Effect of pregnancy on periodontal and dental health. Acta Odontologica Scandinavica. 2002;60(5):257-64.

21. Wandera M, Engebretsen IM, Okullo I, Tumwine JK, Åstrøm AN, Group P-eS. Socio-demographic factors related to periodontal status and tooth loss of pregnant women in Mbale district, Uganda. BMC Oral Health. 2009;9(1):18.

22. Boggess KA. Pathogenicity of periodontal pathogens during pregnancy. American Journal of Obstetrics \& Gynecology. 2005;193(2):311-2.

23. Balan P, Chong YS, Umashankar S, Swarup S, Loke WM, Lopez V, et al. Keystone species in pregnancy gingivitis: a snapshot of oral microbiome during pregnancy and postpartum period. Frontiers in microbiology. 2018;9:2360.

24. Cozier YC, Heaton B, Bethea TN, Freudenheim JL, Garcia RI, Rosenberg L. Predictors of self-reported oral health in the Black Women's Health Study. Journal of public health dentistry. 2020;80(1):70-8.

25. Han K, Kim I, Park Y-G, Park J-B. Associations between the number of natural teeth and the maternal age at childbirth or history of parity in postmenopausal women: the 2010-2012 Korea national health and nutrition examination survey. Advances in Clinical and Experimental Medicine. 2017;26(4):627-33.

26. Ueno M, Ohara S, Inoue M, Tsugane S, Kawaguchi Y. Association between parity and dentition status among Japanese women: Japan public health center-based oral health study. BMC public health. 2013;13(1):993.

27. Amran AG, Alhajj MN, Amran AN. Prevalence and Risk Factors for Clinical Attachment Loss in Adult Yemenis: A Community-Based Study in the City of Dhamar. American Journal of Health Research. 2016;4(3):56-61.

28. Al-Alimi A, Halboub E, Al-Sharabi AK, Taiyeb-Ali T, Jaafar N, Al-Hebshi NN. Independent determinants of periodontitis in Yemeni adults: A case-control study. International journal of dental hygiene. 2018;16(4):503-11.

29. Dhaifullah E, Al-Maweri SA, Al-Motareb F, Halboub E, Elkhatat E, Baroudi K, et al. Periodontal health condition and associated factors among university students, Yemen. Journal of clinical and diagnostic research: JCDR. 2015;9(12):ZC30.

30. Al-Sharabi AK, Shuga-Aldin H, Ghandour I, Al-Hebshi NN. Qat chewing as an independent risk factor for periodontitis: a cross-sectional study. International journal of dentistry. 2013;2013.

31. Sadeq-Ali A-M, AlAkhali M. Oral hygiene and periodontal health status among khat chewers. A casecontrol study. Journal of Clinical and Experimental Dentistry. 2017;9(5):e629. 
32. Al-Maweri SA, Alaizari NA, Al-Sufyani GA. Oral mucosal lesions and their association with tobacco use and qat chewing among Yemeni dental patients. Journal of clinical and experimental dentistry. 2014;6(5):e460.

33. Markou E, Eleana B, Lazaros T, Antonios K. The influence of sex steroid hormones on gingiva of women. The open dentistry journal. 2009;3:114.

34. Russell SL, Ickovics JR, Yaffee RA. Exploring potential pathways between parity and tooth loss among American women. American journal of public health. 2008;98(7):1263-70.

35. Wandera MN, Engebretsen IM, Rwenyonyi CM, Tumwine J, Åstrøm AN, Group P-ES. Periodontal status, tooth loss and self-reported periodontal problems effects on oral impacts on daily performances, OIDP, in pregnant women in Uganda: a cross-sectional study. Health and quality of life outcomes. 2009;7(1):89.

36. Lu H-X, Xu W, Wong MCM, Wei T-Y, Feng X-P. Impact of periodontal conditions on the quality of life of pregnant women: a cross-sectional study. Health and quality of life outcomes. 2015;13(1):67.

37. Christensen K, Gaist D, Jeune B, Vaupel JW. A tooth per child? The Lancet. 1998;352(9137):1387.

38. Al-Maweri SA, Warnakulasuriya S, Samran A. Khat (Catha edulis) and its oral health effects: An updated review. Journal of investigative and clinical dentistry. 2018;9(1):e12288.

39. Halboub E, Dhaifullah E, Abdulhuq M. Khat chewing and smoking effect on oral mucosa: a clinical study. Acta Medica (Hradec Kralove). 2009;52(4):155-8.

40. Al-Maweri SA, Al-Jamaei AA, Al-Sufyani GA, Tarakji B, Shugaa-Addin B. Oral mucosal lesions in elderly dental patients in Sana'a, Yemen. Journal of International Society of Preventive \& Community Dentistry. 2015;5(Suppl 1):S12.

41. Almashraqi AA, Halboub ES, Al-Maweri SA, Barngkgei I, Al-wesabi MA, Al-kamel A, et al. Cone beam computed tomography findings in temporomandibular joint of chronic qat chewers: Dimensional and osteoarthritic changes. Journal of Oral Rehabilitation. 2020.

42. Amran AG, Alhajj MN. Assessment of Gingival Health Status among a Group of Preclinical and Clinical Dental Students at Thamar University, Yemen.

43. Al-Maweri SA, Al-Jamaei A, Saini R, Laronde DM, Sharhan A. White oral mucosal lesions among the Yemeni population and their relation to local oral habits. Journal of investigative and clinical dentistry. 2018;9(2):e12305.

44. Al-Maweri SA, Al-Soneidar WA, AlMaqtari A, Hunaish A, Ghadah A-S, Halboub E. Tobacco Cessation Counseling: Attitudes and Practices among Yemeni Dental Professionals. Journal of Cancer Education. 2018;33(5):1088-93. 